\title{
O ENSINO DE PORTUGUÊS PARA SURDOS: O TEXTO DIDÁTICO E AS RECOMENDAÇÕES DOS PARÂMETROS CURRICULARES NACIONAIS (PCN)
}

\section{Regina Maria de Souza \\ Alice Freire \\ Wilma Favorito}

RESUMO: O presente trabalho analisa um texto didático - voltado para o ensino de português para pessoas surdas - e os Parâmetros Curriculares Nacionais, a partir dos conceitos de formação discursiva e de autoria segundo Foucault $(1995,1996)$. O objetivo é verificar se o livro didático selecionado e os Parâmetros Curriculares Nacionais (BRASIL, 1999) se inscrevem na mesma formação discursiva - ou seja, se se trata da mesma concepção de sujeito surdo nos dois enunciados. E qual é a possibilidade, em termos discursivos, de a surdez ser entendida, em cada um deles, para além dos limites da deficiência.

PALAVRA-CHAVE: Surdez ; Parâmetros curriculares nacionais ; Ensino de português

\begin{abstract}
Based on Foucault's concepts of "discoursive formation" and "authorship", this paper analyzes a textbook - geared to the needs of those interested in the teaching of Portuguese to deaf students - and the Brazilian National Curriculum (Brazil, 1999). The aim of the paper is, therefore, to investigate (1) if the textbook and the official document are inscribed in the same "discoursive formation"; in other words, if the same conception about deaf people are present in both texts; and (2) if is possible, in the context of the same texts, to view deafness, in discourse terms, breaking away from the notion of impairment.
\end{abstract}

KEY-WORDS : Deafness ; The national curriculum; The teaching of portuguese 


\section{INTRODUÇÃO}

Uma das maneiras de se conhecer o status do ensino de português para surdos no Brasil é examinar a produção de textos didáticos pensados para estes sujeitos. A primeira constatação é a raridade de material dessa natureza. $O$ que se encontra, embora em pouco número, são textos que partem da condição auditiva do aluno surdo - a ausência da audição - e suas conseqüências negativas sobre o desenvolvimento da língua oral e escrita. Nesses poucos livros, ou manuais, o leitor pode contar com sugestões de exercícios, formas de hierarquizar as habilidades de leitura e de escrita bem como de desenvolvê-las, a partir de um treinamento persistente que, quase sempre, parte das habilidades supostamente mais simples (reconhecimento de letras do alfabeto, por exemplo) com vistas a se alcançar aquelas (também) supostamente mais complexas ( a compreensão de palavras e frases).

A qualificação do não ouvir como "deficiência", presente nesses textos, produz, como efeito, a invisibilidade da surdez como traço identitário, como marca de inscrição social produzida em um tear que se vale da história e da linguagem como fios principais de constituição. Essa perda de visão do outro surdo parece ser resultado de um ruído, ideologicamente constituído, que não reconhece a possibilidade da existência de outras identidades que "destoem" de um determinado padrão de indivíduo; nesse caso, do chamado padrão de normalidade ouvinte.

\section{O OBJETO DE ESTUDO}

No presente trabalho nossa preocupação será a de analisar como as recomendações ao professor, presentes no texto Português para Deficiente Auditivo (Gotti, 1991), se relacionam com as recentes orientações oferecidas pelos PCN Adaptações Curriculares, editado em 1999. Ou seja, se há um interdiscurso que os reforce mutuamente e se vislumbra-se nos PCN uma visão inovadora,

umaraposta
politicamente correta
que representa
valores simbólicos
importantes,
condizentes com a
igualdade de direitos
e de oportunidades
educacionais para
todos (Brasil, 1999, $\mathrm{p}$.
17).

Dito de modo mais pontual, o presente estudo pretende verificar se o livro didático selecionado e os Parâmetros Curriculares Nacionais (Brasil, 1999) se inscrevem na mesma formação discursiva - ou seja, se se trata da mesma concepção de sujeito surdo nos dois enunciados.

O texto de Gotti (1991) foi escolhido principalmente porque é um material facilmente encontrado em livrarias ou em seus catálogos - e não há, como dissemos, muitas opções. Em segundo lugar é relativamente recente. Em terceiro porque, sendo anterior à publicação dos PCN, pode nos permitir considerar com mais facilidade $\mathrm{O}$ atravessamento e a natureza dos discursos que corporifica os próprios Parâmetros.

\section{PRESSUPOSTOS ASSUMIDOS}

TEÓRICOS

Antes de avançarmos faz-se necessário explicitarmos como serão entendidos, neste estudo, determinados conceitos. Um primeiro é o de autoria, entendido, aqui, de acordo com a abordagem foucualtiana.

Segundo Foucault (1970/1996), o autor não deve ser entendido como
$o$ indivíduo falante
que pronunciou ou escreveu um texto,(...) 


\begin{abstract}
mas como princípio
de agrupamento do

discurso, como

unidade e origem de

suas significações,

como foco de sua

coerência (p.26).
\end{abstract}

A ele se interpela filiação coerente com um conjunto de ditos e verdades aceitos em sua época; se lhe demanda que reflita essa coerência nos agenciamentos lingüísticos que fizer e que, mostrando-se solidários àqueles saberes, possa criar ou produzir um certo efeito de novidade: uma obra é ao mesmo tempo endosso do que já circula e a produção de um enunciado ainda não proferido - combinação de paráfrases e comentários, a criação de pontos de luz em espaços antes escurecidos.

A partir do que foi dito acima, torna-se relevante enfatizar que não é do sujeito empírico, no caso Gotti, que aqui tratamos, como se a mulher Marlene Gotti fosse a origem de seu próprio dizer. Entenderemos sua função de autora como um princípio de organização dos discursos que, ao terem constituído Marlene como educadora de surdos, em sua obra, ela, inescapavelmente, faz falar ${ }^{1}$ ' É a compreensão desses discursos, portanto, que alimenta a presente reflexão.

Um outro conceito que vamos invocar aqui é o de formação discursiva, entendida como um conjunto de enunciados marcados pelas mesmas regularidades, pelas mesmas “regras de formação" (Brandão, 1993,

\footnotetext{
1 Marlene Gotti atualmente trabalha na Secretaria de Educação Especial do MEC e na posição que ocupa tem realizado movimentos de escuta também do outro "surdo" (ou daquele que não se narra "deficiente auditivo"). É possível que os deslocamentos ideológicos, que tais situações dialógicas têm lhe reivindicado, tenham produzidos efeitos ( por exemplo, o rompimento com a noção de "deficiência") não presentes no texto analisado.
}

p. 90). Segundo Foucault (1995) tem-se uma formação discursiva

se se puder mostrar
como qualquer objeto
dor discursor em
questão aí encontra
seu lugar e sua lei de
aparecimento; se se
puder mostrar que ele
pode dar origem,
simultânea ou
sucessivamente, a
objetos que se
excluem, sem que ele
próprio tenha que se
modificar (p.51).

Quanto ao objeto do discurso, ele não preexiste a si mesmo, mas existe sob as condições positivas de um feixe complexo de relações (Foucault, 1995, p. 51). Explicando de outro modo, toda formação produz práticas discursivas (saberes, conhecimentos, verdades) que fabricam tanto o sujeito/objeto de investigação como os métodos para abordá-lo, avaliá-lo, descrever seus comportamentos, esquadrinhar seus segredos e registrar suas falas. Material esse que, transformado em "dados", é discutido, de modo circular, a partir dos mesmos conhecimentos e verdades que engendraram a priori o sujeito - ou seja conciliam-se, com as formações discursivas, princípios de autoperpetuação (veja.Foucault, 1996).

\section{O TEXTO DIDÁTICO E OS PCN - UMA ANÁLISE POSSÍVEL}

O texto de Gotti (1991), daqui para frente apenas "livro didático", tem como meta ensinar o professor a tornar viva e funcional a fala e a escrita para portadores de deficiências da audição, na tentativa de diminuir a lacuna deixada pelas instituições formadoras de educadores. $\mathrm{Na}$ Introdução é reproduzida e sustentada a oposição deficiente auditivo versus indivíduo normal. Essa polarização é construída pelo uso recorrente de termos como 
desvantagem, deficit, inabilidade ( $\mathrm{p}$. 14), atribuídos aos surdos, que explicariam a dificuldade desses indivíduos para a construção do pensamento abstrato ou de idéias complexas, para associação de idéias e de conhecimentos antigos a novos:

Sua percepção tende à subjetividade por falta da percepção acústica. (...) Ele fixa melhor os acontecimentos do que os conceitos. Tem dificuldades em associar idéias, ligar conceitos novos aos antigos, especialmente captar conteúdos abstratos. (p.14)

Nessa linha de argumentação, o livro didático reforça a convicção de que o surdo não teria, sem a fala e a escrita, uma bagagem cultural e social (p. 14), o que dificultaria sua integração na escola e na sociedade, levando-o ao isolamento em suas comunidades e ao uso de uma linguagem limitada $e$ parcial, porque não é compreensível a todos (p. 14).

Já os PCN - Adaptações se propõem a focalizar as necessidades educativas especiais de um modo geral, os alunos que as apresentam $e$ a oferecer aos educadores referências para a identificação dos que podem necessitar de adaptações curriculares (Brasil, 1999, p. 16, grifo nosso). Portanto, os PCN pretendem ser um guia de identificação e de localização daqueles que não sendo como os demais podem necessitar de adaptações curriculares. Há, assim, referência implícita, mas clara, à existência de uma normalidade suposta de comportamento, de desenvolvimento, de linguagem em oposição a qual se produz aqueles que, por dela estarem alheios, demandam "necessidades especiais".

A palavra "identificação", presente nos PCN, colabora na produção desse efeito de sentido. De fato, o termo identificação é definido no Aurélio (Ferreira, 1991, p. 1071) como ato ou efeito de identificar; reconhecimento duma coisa ou dum indivíduo como os próprios . $\mathrm{Na}$ mesma página do Aurélio, lê-se que identificar, é uma palavra que vem do latim, identificare, e significa tornar idêntico, igual; determinar a identidade; determinar a origem, a natureza, as características de; determinar a classificação taxonômica de (organismo); fazer de ( várias coisas) uma só.

Tem-se assim, nos PCN, a manutenção da oposição normal e anormal, a explicitação de formas de identificar o a-normal e o modo de confundi-lo com os normais - as adaptações curriculares.

Como o próprio título do livro didático anuncia, o surdo é considerado deficiente da/na linguagem. Logo nas primeiras páginas pode-se ler: uma das deficiências que o indivíduo pode ter é a surdez (Gotti, 1991, p.13). A criança que nasce surda ou torna-se tal nos dois primeiros anos de vida não terá oportunidade de adquirir pela audição a língua materna (...) De modo geral, a surdez é causa de mutismo (p.13).

A linguagem é concebida assim apenas como o código comum à sociedade majoritária (p. 16). O texto considera o uso da linguagem dos "sinais" como um recurso que só satisfaz a função primária de ter um instrumento de comunicação, aqui concebida como uma limitação lingüística (p.14). A única possibilidade de superação dessa limitação é submetê-los a um processo de oralização que supostamente os aproximaria do padrão de comunicação dos ouvintes. Nessa linha 
argumentativa, pode-se ler no livro: $O$ surdo, apesar de sua deficiência, pode e deve falar (orelha do livro). $\mathrm{Ou}, o$ código, no Brasil, é a língua portuguesa, e o que se pretende é ensinar ao deficiente auditivo esse código, usado pela maioria da sociedade da qual faz parte (...) (p.16).

Nos PCN (Brasil, 1999), o aluno surdo é inserido no conjunto das crianças com condições físicas, intelectuais, sociais, emocionais e sensoriais diferenciadas ( $p$. 23). Notese que a palavra "criança" aqui não apenas nomeia mas qualifica ao excluir adultos e velhos - supostamente fora da escola.

Em relação às mencionadas "condições diferenciadas", elas são entendidas como inerentes à criança $\mathrm{e}$ decorrentes de sua elevada capacidade ou de suas dificuldades para aprender (p. 23) - portanto, uma condição anormal acima ou abaixo do esperado (por quem? - valeria a pena ser perguntado). No caso da pessoa que não ouve, os PCN a enquadram no item Deficiência Auditiva, definida como perda total ou parcial, congênita ou adquirida, da capacidade de compreender a fala por intermédio do ouvido. (p. 25).

No dizer do livro didático (Gotti, 1999), a surdez é relacionada explicitamente ao mutismo ou à mudez. Nos PCN, o mutismo é uma decorrência lógica da definição assumida. Todavia, nos PCN, a relação da surdez com a mudez é deixada implícita.

Constatamos, assim, mais uma coincidência entre o livro didático considerado e os PCN - aquele que não escuta é definido ou como sendo deficiente ou como possuindo uma deficiência. E esta condição lhe impede de falar a partir do suporte da audição, ou seja, pode lhe confinar ao mutismo.
Dizemos que a ausência de audição pode confinar o surdo ao mutismo porque em cada um dos textos apontam-se possibilidades de superação do "problema". O texto didático afirma, por exemplo, que o surdo pode ser resgatado de sua incomunicabilidade pela aquisição da língua oral: a meta do ensino de língua portuguesa. As dificuldades de aprendizagem de português por surdos são atribuídas, primordialmente, à inadequação dos métodos utilizados para esse fim, que não privilegiam o diálogo. Como solução para essa ineficiência, é apresentada, então, uma proposta de ensino para a aquisição de linguagem funcional (p.15) que corresponderia ao uso cotidiano do português.

Linguagem funcional
é toda linguagem
usada no cotidiano,
constituída de
expressões
emocionais,
perguntas, respostas,
ordens e pedidos.
(Gotti, 1999, p. 15,
nota de rodapé no 4)
objetivo do método que
propõe é ensinar o aluno surdo conversar a partir da automatização de enunciados escritos, reduzidos a termos essenciais:

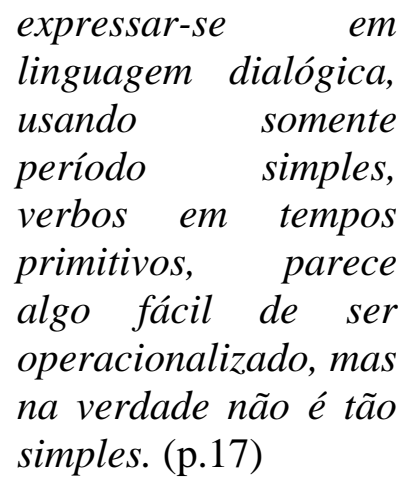

A leitura, em decorrência da assunção de tais pressupostos, torna-se um sub-produto, mero suporte visual, para a aquisição da oralidade que, segundo o livro, permitiria o aparecimento do pensamento 
propriamente dito. Os exercícios, nele sugeridos, são estandardizados e têm como objetivo treinar a "conversação" do aluno e alfabetizá-lo através de recursos como a dramatização, a interpretação de texto e a redação (orelha do livro).

Nos PCN (Brasil,1999), a inclusão dos alunos surdos com ouvintes é tratada como um desafio a ser superado pela escola e pelo próprio aluno. Desafio porque o acesso à informação oral estará interditado ao aluno que não ouve. Como formas de minimizar os efeitos dessa interdição sugerem, como item primeiro, o uso de materiais e equipamentos específicos: prótese auditiva, treinadores de fala, tablado, softwares educativos específicos etc (p. 46). Ou seja, do mutismo pode se escapar estimulandose a oralidade.

Vale a pena notar que o verbo treinar aparece no livro didático. Nos PCN tem-se o termo treinadores, ou seja, faz-se referência à necessidade da presença, na escola, de pessoas cuja função seria treinar o aluno não ouvinte.

A palavra treinar vem do francês antigo traïner, hoje traîner. Verbo transitivo direto, pois sua ação demanda um paciente ou um sujeito que a sofra, tem como significado: Tornar apto, destro, capaz, para determinada tarefa ou atividade (Ferreira, 1991, p. 1995). Cabe-nos, pois, perguntar: para que atividade pretende-se treinar $o$ surdo na escola? A resposta nos PCN é clara: para a fala. São treinadores de fala que sugere, além do uso de próteses e de tablados de madeira.

No texto didático, a escrita e a leitura são ao mesmo tempo atividade fim e atividade treino. $O$ treinamento da fala deve nortear a aquisição daquelas atividades em um jogo permanente de reforço recíproco: quanto mais se fala mais se entende a leitura, quanto mais se lê mais se desenvolve a fala.

Nos PCN (Brasil, 1999), como segunda recomendação ao professor, sugere-se que os textos escritos sejam complementados com elementos que favoreçam a sua compreensão: linguagem gestual, língua de sinais $e$ outros (p. 46). Ou seja, a "linguagem gestual" é definida como um elemento facilitador da compreensão, de natureza instrumental, é sugerida como mediadora/facilitadora da leitura e da escrita em português. Nos PCN, a linguagem dos sinais é classificada com um sistema alternativo de comunicação. E alternativo, como bem se sabe, é um atributo que se aplica a tudo aquilo que pode ser escolhido ou não, que pode ser alternado com outros meios, enfim, algo que em si mesmo não é nem principal e nem constitutivo. Nesse aspecto há total solidariedade com a recomendação do livro didático que reza que: a linguagem de sinais é uma linguagem viva que satisfaz a função primária de ser um instrumento de comunicação (...) mas é limitada e parcial (Gotti, 1991, p. 14).

As recomendações dos $\mathrm{PCN}$ (Brasil, 1999) se direcionam a sugerir condições que possam facilitar, ao surdo, a apreensão das informações expostas verbalmente (p. 47). Portanto, o que os PCN traduzem não é a falta de uma política lingüística mas, pelo contrário, uma clara e forte adesão a uma política lingüística centrada exclusivamente no ensino e na aprendizagem do português. Política, portanto, assumida pelo próprio MEC, órgão responsável pela execução, publicação e divulgação dos parâmetros E novamente aqui há concordância com as idéias defendidas pelo livro didático.

No entanto, há uma diferença importante entre ambos os textos. $\mathrm{O}$ 
livro didático faz ecoar a tese iluminista de que a educação persistente e tenaz pode trazer bons resultados, já que todos os seres humanos, normais ou não, são capazes de aprender via treinamento metódico dos sentidos não comprometidos. Nele há a confiança de que se todos os passos forem seguidos o resultado

é lento, mas existe. Ao
longo dos anos, o
aluno verbaliza, cada
vez mais, de forma
espontânea, er seu
pensamentor
estrutura
logicamenter mais
seqüência
sujeito+verbo+compl
emento (Gotti, 1991,
orelha).

E isto porque como todos os seres humanos, os deficientes auditivos têm uma potencialidade natural para aprender. (p. 87)

Nos PCN não há a mesma esperança nem a mesma certeza. Se houvesse não defenderia, já em seu título, as tais adaptações curriculares. $\mathrm{O}$ pressuposto é que o "portador de necessidade especiais" pode não conseguir atingir objetivos básicos. $\mathrm{Ou}$ seja, pode não compreender determinados conteúdos que, embora essenciais ao currículo, são inviáveis de aquisição por parte do aluno (p. 39). Contrariamente ao livro, que se esforça em sugerir exercícios que poderiam auxiliar na aprendizagem do educando, os PCN criam um fato: o de que haverá conteúdos que naturalmente não serão compreendidos porque extrapolam às possibilidades do aluno. A recomendação é que, então, esses conteúdos sejam eliminados. Nada mais simples.

Os PCN parecem assumir, assim, radicalmente, a tese de que o portador de necessidade especial pode ser intrinsecamente diverso ou diferente dos "normais": não apenas lento em relação a eles mas incapaz de aprender.

A constatação médica/clínica de que a deficiência auditiva é irreversível invade a escola pela via dos PCN que, ao assumi-la como tese, passa a defender as adaptações/eliminações curriculares. Ato necessário para que o outro surdo possa seguir sendo não mais uma imagem distorcida do ouvinte mas mais um diverso da norma, um diferente dela, um deficiente, um deficiente auditivo.

\section{CONCLUSÃO}

A partir das análises feitas anteriormente, concluímos que tanto o texto didático como os PCN se inscrevem na mesma formação discursiva: fabricam o mesmo sujeito surdo (entendido como deficiente) e definem a educação como um processo que pode conduzi-lo às proximidades da normalidade ouvinte. Essa formação se funda em um conjunto de oposições derivadas da invenção da norma e da normalidade no século XVIII (Canguilhem, 1995).

Entretanto, o apelo à norma, ou ao padrão normal, não se restringe à medicina ou à educação especial, mas se constitui a partir de um conjunto solidário de relações disciplinares que, circularmente, o torna necessário: está presente nas normas das fábricas, nas declarações de direitos, nos textos didáticos, nas gramáticas, nas portarias presidenciais, nos dicionários, nos regulamentos das prisões e das escolas, na arquitetura dos hospitais, nas falas cotidianas do senso comum. Em cada sistema disciplinar o que é entendido como "norma" ganha novos sentidos, engendra saberes e em sua dispersão exclui e inclui novos objetos, produz poder, fabrica sujeitos.

No rastro de tais considerações, esse trabalho pretendeu entender que 
sujeito surdo os PCN e o livro didático (re)inventam. E deixar anunciado que neles a surdez como traço identitário, estruturado a partir da língua de sinais, não encontra a menor possibilidade de aparecimento.

\section{REFERÊNCIAS BIBLIOGRÁFICAS}

BRANDÃO, Helena Introdução à análise do discurso. Campinas: Editora da UNICAMP, $2^{\text {a }}$ ed., 1993, 96 p.

BRASIL, Ministério da Educação Parâmetros Curriculares Nacionais Adaptações Curriculares: estratégias para a educação de alunos com necessidades educacionais especiais. Brasília: BRASIL, 1999, 63 p.

CANGUILHEM, Georges O Normal e o Patológico. Rio de Janeiro: Forense, $4^{a}$ edição, 1995, 307 p.

FERREIRA, Aurélio Buarque de Holanda Novo Aurélio Século XXI: o dicionário da língua portuguesa. Rio de Janeiro: Nova Fronteira, 3.ed., 1999, $2128 \mathrm{p}$.

FOUCAULT, Michel Arqueologia do Saber. Rio de Janeiro: Forense, $4^{\text {a }}$ edição, 1995, 239 p.

FOUCAULT, Michel A Ordem do Discurso. São Paulo: Edições Loyola (aula inaugural no Collège de France, pronunciada em 2 de dezembro de 1970), $2^{a}$ edição, 1996, 79 p.

GOTTI, Marlene de Oliveira (1991) Português para Deficiente Auditivo. Brasília: Edunb, 1991, 152 p.

Regina Maria de Souza (UNICAMP/Faculdade de Educação)

Alice Freire

(UFRJ/Faculdade de Letras)

Wilma Favorito

(Instituto Nacional de Educação de Surdos/RJ) 